\title{
Physical Activity Patterns in Adults Who Are Blind as Assessed by Accelerometry
}

\author{
José Marmeleira \\ University of Évora, Research Center in Sports Sciences, Health \\ Sciences, and Human Development
}

Luis Laranjo, Olga Marques

University of Évora

\section{Catarina Pereira}

\section{University of Évora, Research Center in Sports Sciences, Health Sciences, and Human Development}

\begin{abstract}
The main purpose of our study was to quantify, by using accelerometry, daily physical activity (PA) in adults with visual impairments. Sixty-three adults $(34.9 \%$ women) who are blind (18-65 years) wore an accelerometer for at least 3 days (minimum of $10 \mathrm{hr}$ per day), including 1 weekend day. Nineteen participants $(\sim 30 \%)$ reached the recommendation of $30 \mathrm{~min}$ per day of PA, when counting every minute of moderate or greater intensity. No one achieved that goal when considering bouts of at least $10 \mathrm{~min}$. No differences were found between genders in PA measures. Chronological age, age of blindness onset, and body mass index were not associated with PA. We conclude that adults who are blind have low levels of PA and are considerably less active compared with the general population. Health promotion strategies should be implemented to increase daily PA for people with visual impairments.
\end{abstract}

Keywords: visual impairment; physical activity; accelerometry; disability; adults

The regular practice of physical activity is associated with several health benefits and a reduction in risk of all-cause mortality (Garber et al., 2011; Warburton, Nicol, \& Bredin, 2006). Physical activity, especially if performed at a moderate to vigorous intensity, decreases the risk of developing coronary heart disease, stroke, type 2 diabetes, and some forms of cancer (Garber et al., 2011; Pate et al., 1995; U.S. Department of Health and Human Services, Office of Disease Prevention and

José Marmeleira, Luis Laranjo, Olga Marques, and Catarina Pereira are with the Department of Sport and Health at University of Évora, Portugal. José Marmeleira and Catarina Pereira also are members of the Research Center in Sports Sciences, Health Sciences, and Human Development (CIDESD), Portugal. Address author correspondence to José Marmeleira at jmarmel@uevora.pt. 